\title{
Posterior Wall of the Pharynx
}

National Cancer Institute

\section{Source}

National Cancer Institute. Posterior Wall of the Pharynx. NCI Thesaurus. Code C54222.

The dorsal portion of the fibromuscular tube that extends from the skull base to the lower border of the cricoid cartilage, and acts as a conduit for both the digestive and respiratory systems. 